\title{
Is the goal of mastication reached in young dentates, aged dentates and aged denture wearers?
}

\author{
Anne Mishellany-Dutour ${ }^{1}$, Johanne Renaud $^{1,2}$, Marie-Agnès Peyron ${ }^{3}$, Frank Rimek ${ }^{1,4}$ and Alain Woda ${ }^{1,2 *}$ \\ ${ }^{1}$ Univ Clermont 1, UFR Odontologie EA3847, Clermont-Ferrand F-63000, France \\ ${ }^{2}$ CHU Clermont-Ferrand, Service d'Odontologie, Hôtel Dieu, Clermont-Ferrand F-63001, France \\ ${ }^{3}$ Institut National de la Recherche Agronomique, Unité de Nutrition Humaine, Saint-Genès-Champanelle F-63122, France \\ ${ }^{4}$ Rstat, Romans F-79260, France
}

(Received 6 March 2006 - Revised 25 May 2007 - Accepted 31 May 2007)

The objective of the present study was to assess the impact of age and dentition status on masticatory function. A three-arm case-control study was performed. Group 1 ( $n$ 14) was composed of young fully dentate subjects (age 35.6 \pm 10.6 years), group 2 ( $n$ 14) of aged fully dentate subjects (age 68.8 \pm 7.0 years) and group $3(n 14)$ of aged full denture wearers (age 68.1 \pm 7.2 years). Mastication adaptation was assessed in the course of chewing groundnuts and carrots to swallowing threshold. Particle size distribution of the chewed food, electromyographic (EMG) activity of the masseter and temporalis muscles during chewing, and resting and stimulated whole saliva rates were measured. Aged dentate subjects used significantly more chewing strokes to reach swallowing threshold than younger dentate subjects $(P<0 \cdot 05)$, with increased particle size reduction, longer chewing sequence duration $(P<0.05)$ and greater total EMG activity $(P<0.05)$ for both groundnuts and carrots. In addition, aged denture wearers made significantly more chewing strokes than aged dentate subjects $(P<0.001)$ to reach swallowing threshold for groundnuts. Particle size reduction at time of swallowing was significantly poorer for denture wearers than for their aged dentate counterparts, despite an increase in chewing strokes, sequence duration and EMG activity per sequence. Masticatory function was thus adapted to ageing, but was impaired in denture wearers, who failed to adapt fully to their deficient masticatory apparatus.

Mastication: Full dental prostheses: Food bolus: Elderly

Mastication is the first major phase in a series of mechanical and chemical transformations of food, ending in the release of nutrients in blood. The role of mastication in the overall process is now better understood. For example, impaired mastication is known to affect food choice adversely, favouring the selection of an unbalanced diet ${ }^{1,2}$. In turn, reduced variety in selected foods may decrease blood levels of certain nutrients $^{3}$ (see references in Hutton et al. ${ }^{4}$ ). Some less well-documented findings suggest a direct impact of poor mastication on the digestive process (see references in N'Gom \& $\mathrm{Woda}^{5}$ ).

An immediate role of mastication concerns deglutition. Mastication breaks down the food and mixes the resulting particles with saliva to prepare a food bolus that is safe to swallow. To be safe, the food bolus must be smooth, plastic and cohesive $^{6}$. Smoothness and plasticity are needed to facilitate harmless transit past the aero-digestive crossing and then through the oesophagus. Cohesiveness is particularly necessary because otherwise bolus scattering would favour particle aspiration into the airways 6,7 . To obtain such a food bolus, the initial mouthful must be transformed into many smallsized food particles bound together by a mixture of saliva and liquids derived from the food itself ${ }^{6}$. Recent studies have shown that in young healthy subjects the particle size distribution of ready-to-swallow food boluses displays narrow inter-individual variability ${ }^{8}$. This shows that during a usual swallow, the food bolus meets precise particle size conditions, among others, before deglutition is triggered. Fulfilling these conditions is a vital requirement since it helps to prevent dysfunctional deglutition, which is known to be linked to high morbidity ${ }^{9,10}$. An acceptable particle size distribution of the food bolus before swallowing can therefore be considered as a crucial criterion in the assessment of normality of the masticatory function.

A complex motor function such as mastication must adapt to changes that occur in every individual. There are two complementary ways to assess the adaptation of mastication. The first is monitoring the physiological processes involved by simple means such as electromyography or mandibular movement recordings ${ }^{11}$. This approach is known to reflect normal adaptation to food properties, in young ${ }^{12}$ and ageing ${ }^{13,14}$ subjects. Adaptation may, however, become less efficient with larger anatomical changes such as those found, for example, in full denture wearers ${ }^{15,16}$. Full assessment of adaptation thus also requires measuring how well the function performs with respect to the food bolus after mastication, just before swallowing. 
The present study set out to chart the transition from physiological adaptation to pathological impairment of the masticatory function. This was done in a single experiment using several indicators, with three groups of subjects of different ages and with different dental conditions. We hypothesised that failure to attain normal particle size in the ready-to-swallow bolus would be preceded or paralleled by anomalies in the corresponding physiological mastication variables.

\section{Materials and methods}

\section{Subjects and test foods}

Forty-two Caucasian subjects were distributed into three groups of six women and eight men each. Group 1 was composed of young dentate adults (age 24-52 years; mean 35.6 (SEM 10.6) years). Group 2 was composed of aged dentate adults (age 58-82 years; mean 68.8 (SEM 7.0) years). Group 3 was composed of aged full denture wearers (age 53-76 years; mean 68.1 (SEM 7.2) years). Inclusion criteria for groups 1 and 2 were: possession of healthy complete dentition except for third molars, normal maxillo-mandibular relationship, and no removable dentures ${ }^{17}$. Crowns and bridges and other fixed restorations were accepted. The subjects in group 3 had stable lower and upper prostheses and reported no difficulty eating any kind of food. None of the subjects in any of the groups complained of any masticatory disorders, and none had received any dental treatment in the 3 months before experimentation or any medicine that might influence mastication.

Two foods of different texture, namely groundnuts and carrots, were employed as test foods. They contained 9 and $87 \%$ water respectively. Portions were five nuts (each portion $2.5-3.5 \mathrm{~g}$ ) and cylindrical samples cut from raw carrots (height $1 \mathrm{~cm}$; diameter $2 \mathrm{~cm}$; weight $3-4 \mathrm{~g}$ ).

\section{Salivary flow measurements}

For collection of the saliva samples before masticatory recording, the subject was seated comfortably, with eyes open, in a part of the laboratory with restricted access to provide a restful and quiet environment. Unstimulated whole saliva was collected for a single $5 \mathrm{~min}$ period by having the subject bend his/her head forward to let the saliva drain into a graded sampling tube. The parotid saliva was then stimulated by chewing $1 \mathrm{~g}$ paraffin $\left(\mathrm{CRT}^{\circledR}\right.$ kit; Ivoclar Vivadent, Schaan, Liechtenstein). During the first minute, saliva was not collected and the subject could swallow. Stimulated saliva was collected over the following $5 \mathrm{~min}$ period.

\section{Masticatory recordings}

Muscular activity was recorded by surface electromyography from both left and right masseter and temporal muscles during chewing of the two test foods. The experimental setup is described in detail in a previous study ${ }^{17}$. The variables calculated from the electromyographic (EMG) signals for each masticatory sequence were: number of masticatory cycles, duration of the sequence, mean frequency of mastication (number of cycles/duration of sequence), mean activity per cycle for the four muscles (EMG activity per cycle), and summed EMG activities of the four muscles for all cycles (EMG activity per sequence) $^{14}$.

\section{Particle size measurements}

Particle size was measured by the sieving method. The expectorated boluses were washed on a $0.4 \mathrm{~mm}$ sieve for $1 \mathrm{~min}$ in running water and dried $\left(40^{\circ} \mathrm{C} ; 1 \mathrm{~h}\right)$. The boluses were then poured through a stack of seven sieves with apertures of 4, 2.5, 2, 1.4, 1, 0.8 and 0.4 mm (Saulas, Paisy Cosdon, France). The fractions retained on each of the seven sieves were weighed, and the masses were expressed as a percentage of the initial mass of the mouthful before mastication and also as cumulative percentages of the collected masses of the boluses.

\section{Experimental procedure}

Each subject attended two sessions lasting $1 \mathrm{~h}$ each. During the sessions, the subjects were instructed to chew in a usual manner. Subjects had been asked to have a meal between 1 and $2 \mathrm{~h}$ before the experimentation to reduce possible variations due to desire to swallow. The first session was designed to familiarise the subjects with the experimental context. EMG activity recording, food bolus sampling for granulometric analysis and salivary flow collection were carried out during the second session. The session consisted of eight masticatory sequences during which eight samples of the same test food were chewed (Table 1). For all the subjects, food samples 1 and 2 were chewed and swallowed, and the masticatory sequences were recorded by electromyography. Samples 3 and 4 were used to train subjects to detect swallowing threshold and to expectorate just before swallowing. Samples 5-8 of the second session were used for granulometry and EMG recording analyses. Since it is known that there is no effect of repetition, the EMG and granulometric values from sequences 5-8 were averaged ${ }^{8,12,18}$. During each session, the eight masticatory sequences were performed for groundnuts and then for carrots.

The subjects placed the food sample in their mouths. They were instructed to close their mouths before starting to chew. They then placed the food between their teeth and, on a signal from the experimenter, began to chew. After each sequence, they rinsed their mouths freely with water $(26 \mathrm{ml})$, until they felt they had cleared all the food particles. The remains of samples 5-8 were added to the expectorated boluses.

Informed consent was obtained from all the subjects. This protocol was accepted by the local ethics committee.

\section{Statistical analysis}

Analyses of EMG recordings, salivary flow measurements and particle size distribution were performed using SPSS software (version 14 for Windows, 2005; SPSS Inc., Chicago, IL, USA). Each model was simplified following its likelihood. Group comparisons were adjusted using Sidak's rule $(P<0 \cdot 05)$. Sidak's test is designed for pairwise comparisons ${ }^{19}$.

For EMG data, a mixed model was run with group (young dentate, aged dentate and aged denture wearers) and sex as fixed factors and subject as a random effect. These analyses were performed separately for groundnuts and carrots as it had already been shown that no correlation was to be expected between these two foods ${ }^{8,18}$. Independent analyses 
Table 1. Design of the second session of mastication recording and data analyses*

\begin{tabular}{l} 
Samples $\begin{array}{c}\text { Training for the } \\
\text { detection of intention } \\
\text { to swallow }\end{array}$ \\
\hline $\begin{array}{c}\text { Samples analysed } \\
\text { by sieving }\end{array}$ \\
2. Swallowed \\
3. Expectorated \\
4. Expectorated \\
5. Expectorated \\
6. Expectorated \\
7. Expectorated \\
8. Expectorated \\
EMG, electromyographic. \\
*A first session had been carried out previously with the exclusive aim of training subjects. The eight food \\
samples were chewed and only the first two were swallowed. The first four samples were primarily used to \\
train the subjects for self-detection of the intention to swallow. EMG recordings performed with the first two \\
samples were used as a secondary objective, to compare EMG values when subjects swallowed or expecto- \\
rated the food boluses. The complete procedure was performed for groundnuts and carrots. The whole pro- \\
cedure was preceded by saliva collection.
\end{tabular}

were conducted for each of the five measured variables (number of cycles, sequence duration, cycle frequency, and EMG activity per cycle and per sequence). The effect of expectoration on the masticatory process was explored as a secondary objective. This effect was not taken into account in the above analyses, which were conducted on values obtained only with expectorated boluses. We compared one EMG recording followed by swallowing (sample 1 in Table 1) with one recording followed by expectoration (sample 5 in Table 1). Group and sex were included as between-subject factors and the mode (expectorated or swallowed) as a repeated within-subject factor. Similar models were built for each of the five measured EMG variables (number of masticatory cycles, duration of the sequence, mean cycle frequency, mean EMG activity per cycle and per sequence) and for each of the two foods (groundnuts and carrots).

For the salivary flow, a mixed model was run with group (young dentate, aged dentate and aged denture wearers), sex and their level 2 interactions as fixed factors and mode of salivation (stimulated and unstimulated) and session as repeated within-subject factors.

Two repeated-measures mixed models, one for each food, were run for the particle size analysis of the boluses. Group (young dentate, aged dentate and aged denture wearers), sieve and level 2 subsequent relevant interactions were included as fixed factors. Sex and subsequent relevant interactions were withdrawn from the model because of irrelevancy. Sieve factor remained as the repeated within-subjects factor. The bolus mass retained in each sieve was the measured variable, which was repeated through seven sieves. It was calculated as a percentage of the initial mass of the food sample. As the dispersion tends to augment with this percentage, the response variable modelled was the result of the square root transformation.

\section{Results}

Physiological variables of the mastication process

Comparison between young and aged dentate subjects showed a strong increase in the aged group in the number of cycles, sequence duration and EMG activity per sequence (Fig. 1 and Table 2). No significant difference was found for either
EMG activity per cycle or cycle frequency. A further increase in number of cycles, sequence duration and EMG activity per sequence was observed in the aged denture wearers when this group was compared with the aged dentate subjects (Fig. 1 and Table 2). These increases were observed for both test foods. No significant difference in the EMG activity per cycle between the two aged groups was found and a significant difference in cycle frequency was observed comparing the aged dentate subjects with denture wearers only for carrots. The effect of sex found for sequence duration, cycle frequency and EMG activity per cycle and sequence is shown in Table 2.

The comparison between EMG values recorded before expectorating or swallowing the food indicated no significant difference for any of the variables except the cycle frequency with carrots $(F(1,35)=7 ; P<0 \cdot 05)$. The interaction between expectorating and swallowing and group factors $(F(2,35)=3 \cdot 6$; $P<0.05)$ indicated that this effect corresponded to an increased mastication frequency when the aged dentates expectorated the bolus.

\section{Salivary flows}

Large differences between the stimulated and unstimulated mode were observed $(P<0.001)$. Values were 0.27 (SEM 0.05 ) and 1.82 (SEM 0.20$) \mathrm{ml} / \mathrm{min}$ for young dentate subjects, 0.23 (SEM 0.0 ) and 2.12 (SEM 0.27 ) $\mathrm{ml} / \mathrm{min}$ for aged dentate subjects and 0.19 (SEM 0.17) and 1.85 (SEM 0.98) $\mathrm{ml} / \mathrm{min}$ for aged denture wearers (Fig. 2). No significant difference in salivary flow was found for group, sex or interaction between factors or between sessions.

\section{Particle size distribution in food bolus}

The mass of the expectorated boluses was considerably lower than the mass of the initial mouthful: only 34.2 (SEM 1.2) \% and 32.4 (SEM 1.2) \% of the mass of groundnuts was recovered in the young and aged dentate subjects respectively. More of the initial food mass was recovered in the aged denture wearers group: 54.9 (SEM 1.7) \% of the initial mass of the mouthful was collected. The corresponding values for carrots were 35.9 (SEM 1.9), 29.4 (SEM 1.7) and 53.9 (SEM 1.8) \%. 
(A)

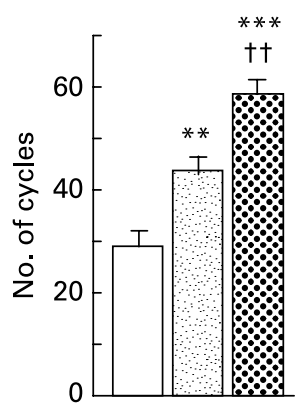

(F)

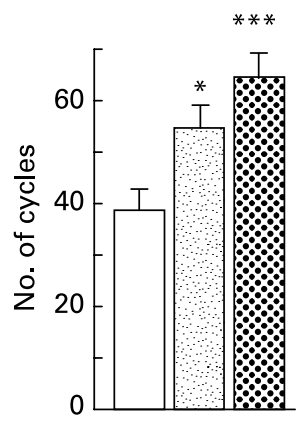

(B)

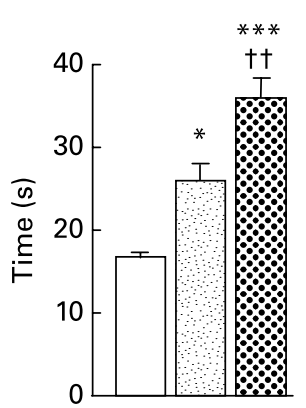

(G)

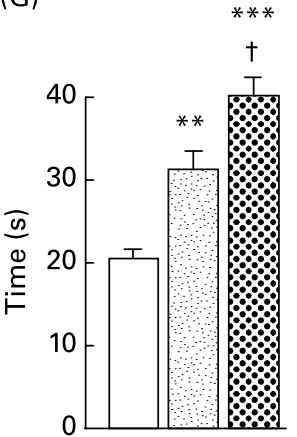

(C)

(D)

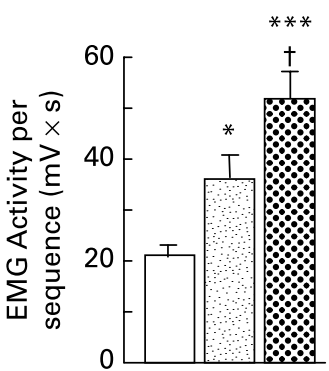

(H)

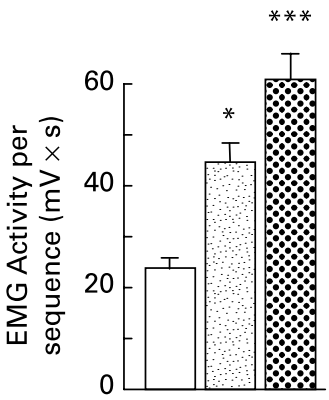

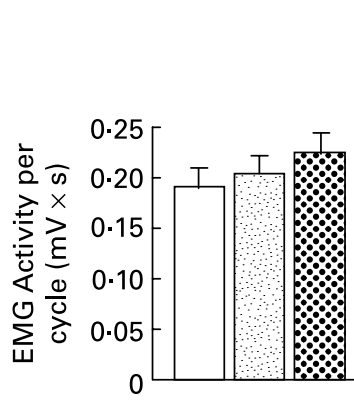

(I)

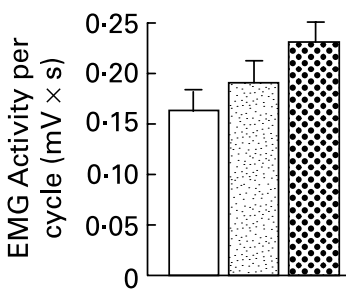

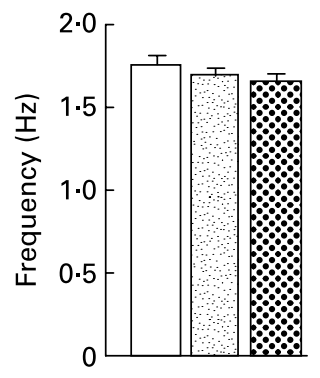

(E)

(J)

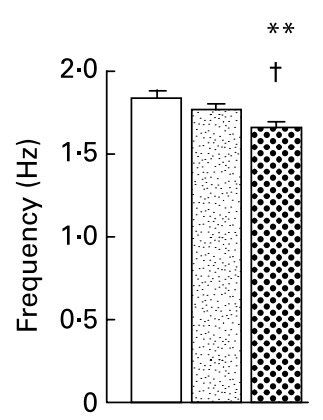

Fig. 1. Values of variables obtained by electromyographic (EMG) recordings of mastication in three groups of fourteen subjects (young dentate subjects ( $\square$ ), aged dentate subjects $(\square)$ and aged denture wearers ( 8$)$ ). Number of cycles (A, F), duration of sequence of mastication (B, G), mean EMG activity per sequence $(C, H)$ and per cycle $(D, I)$ and cycle frequency $(E, J)$ were measured from EMG recordings. Two test foods were studied, groundnut $(A-E)$ and carrot $(F-J)$. Values are means, with their standard errors represented by vertical bars. Mean value was significantly different from that of young dentate subjects: ${ }^{\star} P<0.05$, ${ }^{\star \star} P<0.01,{ }^{\star \star \star} P<0.001$. Mean value was significantly different from that of aged dentate subjects: $\dagger P<0.05, \dagger \dagger P<0.01$.

The mixed models indicated no sex effect for either groundnuts or carrots. The model also showed a group effect $(F(2,39)=24 ; P<0.001$ for groundnuts and $F(2,39)=14$; $P<0.001$ for carrots), and a sieve effect $(F(6,39)=222$; $P<0.001$ for groundnuts and $F(6,39)=271 ; P<0.001$ for carrots). The distribution of particle size was significantly different across groups as indicated by the significant interactions between group and sieve factors $(F(12,39)=11$; $P<0.001$ for groundnuts and $F(12,39)=8 ; P<0.001$ for carrots). As shown in Fig. 3 (B), the particle size distribution curves obtained from young and aged dentate subjects chewing groundnuts were superimposable and not significantly different. However, when they ate carrots, the aged dentate subjects produced more small particles and fewer large particles than the younger ones. The distributions of particle sizes produced by the aged denture wearers were markedly different from those from the aged dentate subjects. Many more large particles were present in the food boluses made by the denture wearers for both groundnuts and carrots. The same results, expressed as a percentage of the recovered bolus mass, are illustrated in cumulative curves (Fig. 3 (B)). This figure shows that the curves of cumulative mass of groundnut and carrot particles produced by the aged dentate subjects are above the curve of the young dentates, indicating that their food bolus was more fully comminuted, since it contained more small particles. On average, $60 \%$ of groundnut particle diameters were between 0.4 and $1.4 \mathrm{~mm}$ for healthy young subjects. Up to $70 \%$ were in this range for aged dentate subjects. By contrast, only $35.5 \%$ of particles were in this range in the denture wearer group.

\section{Discussion}

\section{Limits of the study}

In the present study, granulometry results describe the full distribution range of particle sizes characterising the boluses at the time of natural deglutition. This contrasts with the use, in many previous studies ${ }^{1,13,20-23}$, of a single value schematising chewing ability rather than characterising boluses. In these studies, the boluses were obtained after instructing the subjects to chew for a preset time or for a preset number of strokes (masticatory efficiency). However, this approach, often used with non-edible products ${ }^{21,23-26}$, restricts the amount of information obtained, since only one sieve is generally used ${ }^{1,13,22}$.

A large proportion of the initial mass of the test food was lost during the chewing process. This mass loss may be explained by intermediate deglutition occurring in the course of natural mastication of edible food in nearly $80 \%$ of masticatory sequences ${ }^{27}$. Mass loss may result from the transport of bolus fractions but also from the liquid content, water for carrots and oil for groundnuts, released by the food and loaded with soluble nutrients. Obviously, the particle size distribution of the collected mass of food may be somewhat different from the distribution of the whole swallowed particle mass, and this is a limit in the present study.

Mastication physiology was studied with a limited number of variables. Inter-individual variability was not considered in the present study because its effect is not controversial ${ }^{14}$. Dependent variables were also restricted to those (number of cycles, duration of the sequence, mean cycle frequency, and EMG activities per cycle and per sequence) that have been shown to be the most discriminant for texture or age changes ${ }^{12,14}$. 


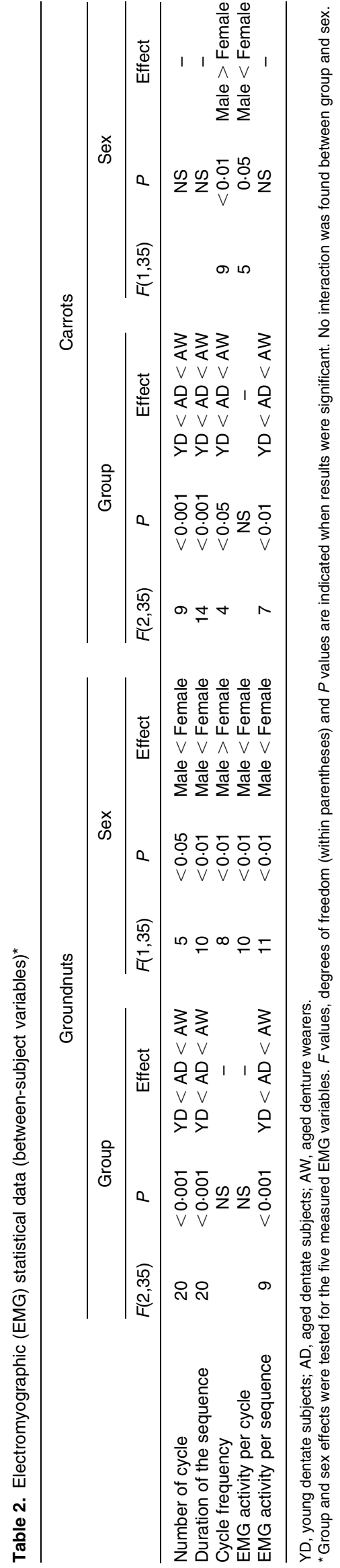

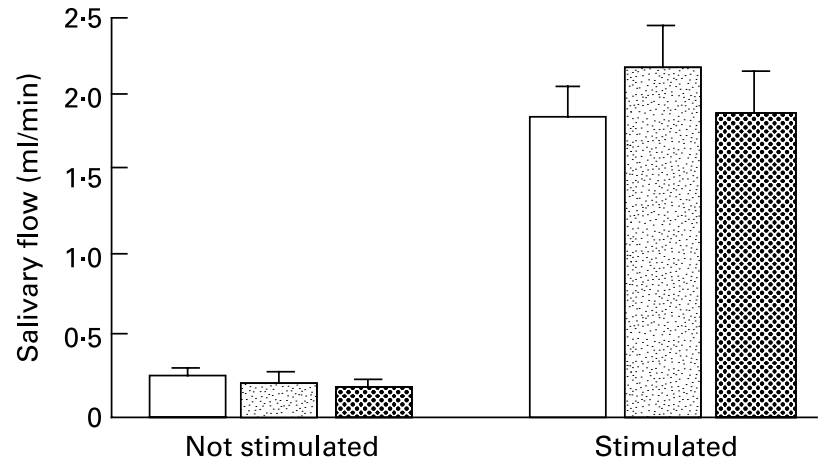

Fig. 2. Unstimulated and paraffin-stimulated saliva flow rates over a $5 \mathrm{~min}$ period for all subjects (young dentate subjects $(\square$ ), aged dentate subjects $(\square)$ and aged denture wearers ( $\mathbf{0})$ ). Values are mean flow rates for fourteen subjects per group, with their standard errors represented by vertical bars. A significant effect $(P<0.001)$ was found only between the two modes of salivation.

\section{Adaptation of mastication with ageing}

Ageing is associated with a decline in the masticatory apparatus, resulting in a decreased maximal bite force ${ }^{22}$ and a loss of muscle mass ${ }^{28}$. The present results confirm that if confounding factors such as missing teeth are controlled for, then ageing alone has little impact on the ability of subjects to reduce food into small particles ${ }^{1,13,21,22,29}$. Thus the objective of chewing, which is to make a smooth, plastic and cohesive food bolus ${ }^{6}$, is still achieved despite ageing of the masticatory apparatus.

The present results also indicate that the formation of a food bolus ready to be swallowed uses more energy in aged subjects ${ }^{13,14}$. The adaptation of the masticatory function to ageing is seen in an increase in the values of the EMG activity per sequence and its two related variables: number of cycles and sequence duration. The EMG per cycle was not significantly different between the two dentate groups ${ }^{13,14}$.

The food bolus of the aged dentate group was made up of finer particles than the bolus of the younger group. This better performance of the aged dentate group occurred in parallel with an increased number of cycles, duration of sequence and EMG activity per sequence. Hence the increase in the EMG activity per sequence cannot be interpreted as a need in the older subjects to compensate for the decreased efficiency of their masticatory apparatus, since the aged subjects could have stopped chewing once the pulverisation level found in the young subjects was reached. The present results show that the goal of constituting a satisfactory food bolus similar to those made by the young subjects was thus actually exceeded in the aged dentate group. This extra comminution of the food may be explained in various ways. Rather than compensating for decreased masticatory performance, the increased muscular work recorded in the aged subjects may be the response to a need for a more fragmented food because of a less efficient digestive apparatus. The increased muscular work may also be due to decreased oral sensitivity ${ }^{30}$, causing older subjects to take greater care to be sure of swallowing a safe bolus. It could also be due to more leisurely eating.

The size of the particles in the bolus is not the only variable that triggers the swallow: the amount of fluid entering the bolus must also be taken into account ${ }^{6}$. The aged subjects 
(A)

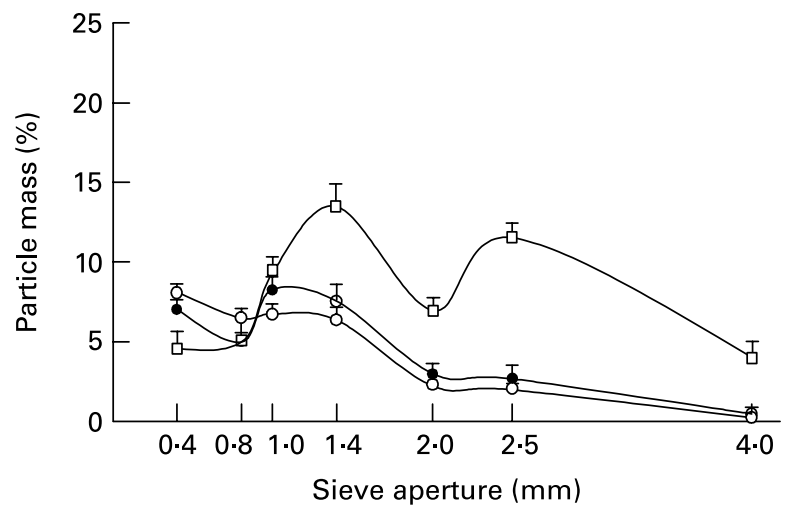

(C)

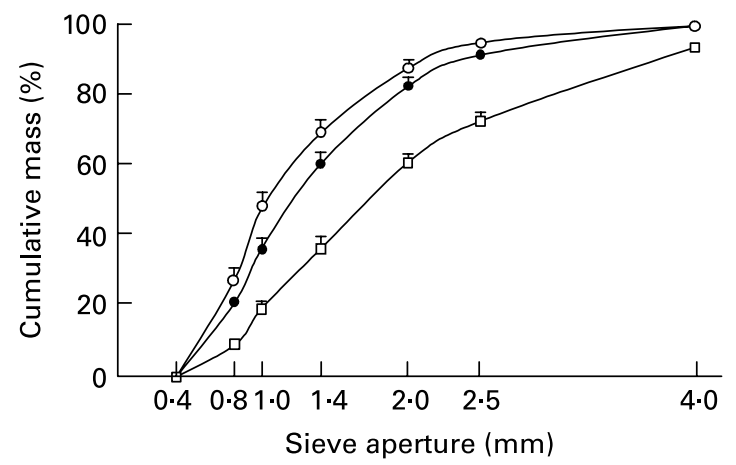

(B)

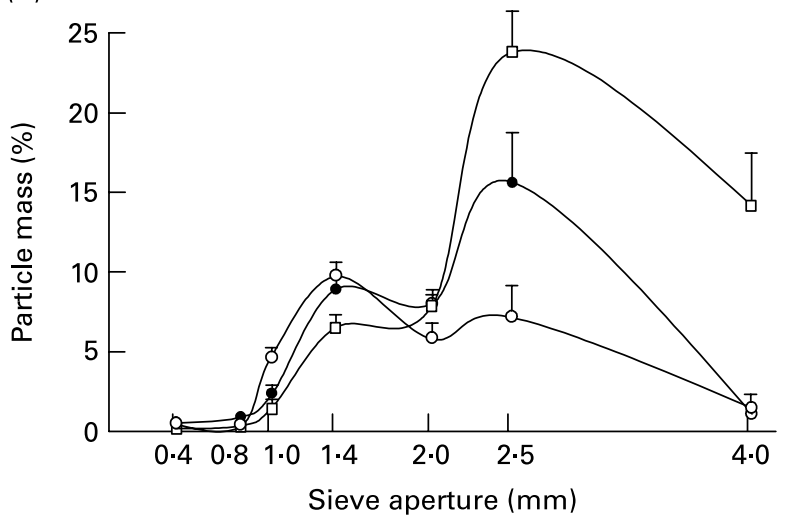

(D)

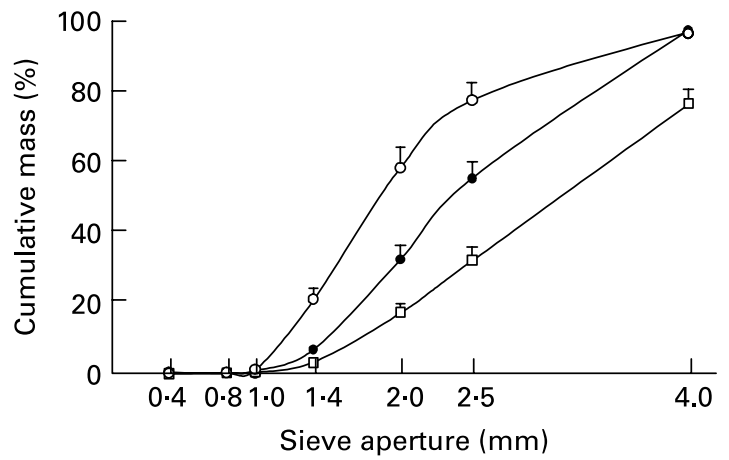

Fig. 3. Distribution of groundnut $(A, C)$ and carrot $(B, D)$ particles in three groups of fourteen subjects (young dentate subjects $(\bullet)$, aged dentate subjects $(O)$ and aged denture wearers $(\square)$ ). (A and B) Distribution of the mean mass through the seven sieves. Values are mean percentages of the initial mass for each of the sieves, with their standard errors represented by vertical bars. The measurements were made on expectorated boluses obtained after a complete chewing sequence and just before swallowing. ( $C$ and $D$ ) Cumulative percentages of mean mass recovered from each of the seven diameter classes of particles. Values are calculated as percentages of the bolus masses collected before swallowing, with their standard errors represented by vertical bars.

may have chewed longer than the young subjects because the time of optimal insalivation took longer to reach. This delay does not seem to result from a decreased salivary flow, given the lack of change with ageing demonstrated in the present and other studies ${ }^{15,31}$. However, the composition of the saliva might be an important factor not studied here. Dissociation between a preserved saliva flow and an impaired saliva composition has been described in ageing subjects ${ }^{32}$. A deficit in mucin content ${ }^{33}$ could, for example, lengthen the time needed to constitute a cohesive food bolus.

\section{Impaired mastication in full denture wearers}

Previous studies focusing on full removable dentures showed that masticatory efficiency was decreased by 50 to $85 \%$ compared with subjects with intact dentition ${ }^{29,34-37}$. In line with these results, we found that denture wearers made a much coarser bolus than dentate subjects ${ }^{1,16,21}$.

We show that mastication in denture wearers reflects an effort to adapt to their masticatory apparatus deficiency even with an easy-to-chew food such as groundnuts. This led to an increase in the number of chewing cycles, duration of mastication sequence and EMG activity per sequence, confirming preliminary data obtained with other foods ${ }^{16,24,36,38}$. It must be noted that despite this increased energy expenditure, denture wearers had difficulty making a food bolus with small enough particles. With carrots, a food more difficult to chew than groundnuts ${ }^{1,39,40}$, edentate subjects had to strive even harder. This resulted in more EMG activity and a poorly prepared food bolus containing many large particles.

We found no significant difference in the EMG per cycle value between the groups. Other studies have found an increase $^{41}$ or a decrease in EMG activity per cycle in denture wearers ${ }^{15,16,42}$. Many factors such as the experimental instructions given for chewing, the type of food, whether edible or not, or divisible or not, and the quality of the full dentures, may modify muscle activity per cycle. These differences between studies contrast with the increased number of cycles and the increased EMG activity over the complete sequences that are always found in studies with denture wearers. This suggests that the level of EMG activity per cycle reflects an optional process used by these subjects to strive to make a satisfactory food bolus.

Finally, when an even more difficult-to-chew food is offered, such as meat, full denture wearers may not accomplish mastication. They reject the food or display a markedly decreased EMG activity ${ }^{42}$, indicating that non-prepared pieces of food are being swallowed.

These different findings suggest that the adaptation ability of denture wearers was overstretched and that full denture wearers were outside the normal physiological range. Full denture wearers must therefore be considered as a group of 
subjects with impaired mastication, as they fail to adapt to their masticatory apparatus deficiency. This impaired mastication is known to impact on the digestive process, and indirect evidence suggests that nutritional status and systemic general health may be compromised ${ }^{4,5}$.

\section{Masticatory frequency as a criterion}

The present study shows the frequency of cycles within the sequence to be a key variable for the evaluation of mastication. Previous studies have shown that frequency is the chewing parameter with the most repeatable values between trials ${ }^{43}$. It has also been shown that for a given food, only minimal variations occur as the hardness of the same food is increased. This was observed with natural foods ${ }^{44}$ and with materials - either edible food or elastomers - which independently of hardness displayed a constant elastic rheological property ${ }^{12,14,16}$. The present study also confirms that masticatory frequency is not modified by ageing ${ }^{14}$. At the other end of the range, disabled individuals with Down's syndrome present a marked decrease in cycle frequency compared with healthy controls. This decrease has been observed with different solid foods and reached $50 \%$ with carrots ${ }^{45}$. A similar decrease in mastication frequency is also reported in subjects with temporo-mandibular disorders ${ }^{46}$. The denture wearers observed in the present study showed intermediate behaviour: a significant decrease in cycle frequency was only observed when chewing hard food (carrots) and this decrease was moderate $(8.8 \%)$. We suggest that constant mean cycle frequency could be used as a criterion of good masticatory health. Conversely, a marked deviation from the median frequency values could be indicative of an impaired masticatory function. However, it must be noted that frequency displays a large interindividual variability ${ }^{17,47}$, differences between men and women $^{14,43,48}$, and changes with mouthful size or rheological properties of natural foods ${ }^{47-52}$. Therefore, in the present study, the differences found between young and aged dentate subjects in number of cycles, sequence duration and EMG activity per sequence must be considered as within the normal adaptation range, whereas the changes in the cycle frequency observed in the aged denture wearers are indicative of an impairment of masticatory processing.

\section{Consequences for nutrition}

The present results confirm that oral health affects the masticatory process. Denture wearers have difficulty chewing some foods. This may induce at least two different behaviours. Many studies have shown that denture wearers either modify their diet or chew less ${ }^{1,53-55}$. Changing diet leads to inadequate food intake and may induce a specific nutrient deficiency. Chewing less may also result in a lower nutrient bioavailability and an impaired nutritional status ${ }^{2-4,56}$ since intestinal transit kinetics may be slowed by an insufficiently disorganised food matrix.

\section{Conclusion}

In conclusion, these results demonstrate that compared with young fully dentate subjects, aged individuals with similar dentition require more strokes to reach a swallowing threshold and as a result achieve greater particle size reduction. With the increased number of strokes, corresponding increases in masticatory muscle EMG and chewing sequence duration were observed. The present study also shows that after replacement of the natural teeth by removable full dentures, mastication can be considered as impaired, since the food bolus contained much coarser particles than for their dentate contemporaries in spite of an increased number of cycles and EMG activity. The study also suggests that masticatory frequency within the sequence could serve as a criterion to evaluate the status of the masticatory function.

\section{Acknowledgements}

We are indebted to Richard Ryan for language editing. Funding was provided exclusively by the French Department of Research and the Institut National de la Recherche Agronomique (INRA).

\section{References}

1. Wayler AH \& Chauncey HH (1983) Impact of complete dentures and impaired natural dentition on masticatory performance and food choice in healthy aging men. J Prosthet Dent 49, 427-433.

2. Sheiham A, Steele JG, Marcenes W, Lowe C, Finch S, Bates CJ, Prentice A \& Walls AW (2001) The relationship among dental status, nutrient intake, and nutritional status in older people. J Dent Res 80, 408-413.

3. Morais JA, Heydecke G, Pawliuk J, Lund JP \& Feine JS (2003) The effects of mandibular two-implant overdentures on nutrition in elderly edentulous individuals. J Dent Res 82, 53-58.

4. Hutton B, Feine J \& Morais J (2002) Is there an association between edentulism and nutritional state? J Can Dent Assoc 68, $182-187$.

5. N'Gom PI \& Woda A (2002) Influence of impaired mastication on nutrition. J Prosthet Dent 87, 667-673.

6. Prinz JF \& Lucas PW (1997) An optimization model for mastication and swallowing in mammals. Proc Biol Sci 264, 1715-1721.

7. Palmer JB \& Hiiemae KM (2003) Eating and breathing: interactions between respiration and feeding on solid food. Dysphagia 18, 169-178.

8. Peyron MA, Mishellany A \& Woda A (2004) Particle size distribution of food boluses after mastication of six natural foods. J Dent Res 83, 578-582.

9. Johnston BT, Li Q, Castell JA \& Castell DO (1995) Swallowing and oesophageal function in Parkinson's disease. Am J Gastroenterol 90, 1741-1746.

10. Hennequin M, Veyrune JL \& Bourdiol P (1999) Significance of oral health in persons with Down syndrome: a literature review. Dev Med Child Neurol 41, 275-283.

11. Woda A, Foster K, Mishellany A \& Peyron MA (2006) Adaptation of healthy mastication to factors pertaining to the individual or to the food. Physiol Behav 89, 28-35.

12. Peyron MA, Lassauzay C \& Woda A (2002) Effects of increased hardness on jaw movement and muscle activity during chewing of visco-elastic model foods. Exp Brain Res 142, 41-51.

13. Feldman RS, Kapur KK, Alman JE \& Chauncey HH (1980) Aging and mastication: changes in performance and in the swallowing threshold with natural dentition. J Am Geriatric Soc $\mathbf{2 8}$ $97-103$.

14. Peyron MA, Blanc O, Lund JP \& Woda A (2004) Influence of age on adaptability of human mastication. J Neurophysiol 92, 773-779. 
15. Kapur KK \& Garrett NR (1984) Studies of biologic parameters for denture design. Part II: Comparison of masseter muscle activity, masticatory performance, and salivary secretion rates between denture and natural dentition groups. $J$ Prosthet Dent 52, 408-413.

16. Slagter AP, Bosman F, Van der Glas HW \& Van der Bilt A (1993) Human jaw-elevator muscle activity and food comminution in dentate and edentulous state. Arch Oral Biol 38, 195-205.

17. Lassauzay C, Peyron MA, Albuisson E, Dransfield E \& Woda A (2000) Variability of the masticatory process during chewing of elastic model foods. Eur J Oral Sci 108, 484-492.

18. Mishellany A, Woda A, Labas R \& Peyron MA (2006) The challenge of mastication: preparing a bolus suitable for deglutition? Dysphagia 21, 87-94.

19. Games PA (1977) An improved $t$ table for simultaneous control on g contrasts. J Am Stat Assoc 72, 531-534.

20. Carlsson GE (1974) Bite force and chewing efficiency. Front Oral Physiol 1, 265-292.

21. Fontijn-Tekamp FA, Slagter AP, Van der Bilt A, Van't Hof MA, Witter DJ, Kalk W \& Jansen JA (2000) Biting and chewing in overdentures, full dentures, and natural dentitions. J Dent Res 79, 1519-1524.

22. Hatch JP, Shinkai RSA, Sakai S, Rugh JD \& Paunovich ED (2001) Determinants of masticatory performance in dentate adults. Archs Oral Biol 46, 641-648.

23. Fontijn-Tekamp FA, Van der Bilt A, Abbink JH \& Bosman F (2004) Swallowing threshold and masticatory performance in dentate subjects. Physiol Behav 83, 431-436.

24. Slagter AP, Olthoff LW, Steen WH \& Bosman F (1992) Comminution of food by complete-denture wearers. J Dent Res $\mathbf{7 1}$, 380-386.

25. English JD, Buschang PH \& Throckmorton GS (2002) Does malocclusion affect masticatory performance? Angle Orthod 72, 21-27.

26. N'Gom PI, Diagne F, Aidara-Tamba AW \& Sene A (2007) Relationship between orthodontic anomalies and masticatory function in adult subjects. Am J Orthod Dentofacial Orthop 131, 216-222.

27. Hiiemae K, Heath MR, Heath G, Kazazoglu E, Murray J, Sapper D \& Hamblett K (1996) Natural bites, food consistency and feeding behaviour in man. Arch Oral Biol 41, 175-189.

28. Newton JP, Abel RW, Robertson EM \& Yemm R (1987) Changes in human masseter and medial pterigoid muscles with age: a study by computed tomography. Gerondontics $\mathbf{3}, 151-154$.

29. Carlsson GE (1984) Masticatory efficiency: the effect of age, the loss of teeth and prosthetic rehabilitation. Int Dent J 34, 93-97.

30. Mantecchini G, Bassi F, Pera P \& Preti G (1998) Oral stereognosis in edentulous subjects rehabilitated with complete removable dentures. J Oral Rehabil 25, 185-189.

31. Bourdiol P, Mioche L \& Monier S (2004) Effect of age on salivary flow obtained under feeding and non-feeding conditions. J Oral Rehabil 31, 445-452.

32. Nagler RM \& Hershkovitch O (2005) Relationships between age, drugs, oral sensorial complaints and salivary profile. Arch Oral Biol 50, 7-16.

33. Navazesh M, Mulligan RA, Kipnis V, Denny PA \& Denny PC (1992) Comparison of whole saliva flow rates and mucin concentrations in healthy Caucasian young and aged adults. $J$ Dent Res 71, 1275-1278.

34. Kapur KK, Soman S \& Yurkstas A (1964) Test foods for measuring masticatory performance of denture wearers. J Prosthet Dent 14, 483-491.

35. Feldman RS (1983) Age, masticatory ability and swallowing. Nutr Rev 41, 344-346.

36. Wayler AH, Muench ME, Kapur KK \& Chauncey HH (1984) Masticatory performance and food acceptability in persons with removable partial dentures, full dentures and intact natural dentition. J Gerontol 39, 284-289.

37. Garcia RI \& Perlmuter LC (1989) Effects of dentition status and personality on masticatory performance and food acceptability. Dysphagia 4, 121-126.

38. Jemt T (1981) Chewing patterns in dentate and complete denture wearers - recorded by light-emitting diodes. Swed Dent $J$ 5, 199-205.

39. Wayler AH, Kapur KK, Feldman RS \& Chauncey HH (1982) Effects of age and dentition status on measures of food acceptability. J Gerontol 37, 294-299.

40. Agrawal KR, Lucas PW, Prinz JF \& Bruce IC (1997) Mechanical properties of foods responsible for resisting food breakdown in the human mouth. Arch Oral Biol 42, 1-9.

41. Veyrune JL, Lassauzay C, Nicolas E, Peyron MA \& Woda A (In the Press) Mastication of model products in complete denture wearers. Archs Oral Bioi.

42. Veyrune JL \& Mioche L (2000) Complete denture wearers: electromyography of mastication and texture perception whilst eating meat. Eur J Oral Sci 108, 83-92.

43. Youssef RE, Throckmorton GS, Ellis E III \& Sinn DP (1997) Comparison of habitual patterns in men and women using a custom computer program. J Prosthet Dent 78, 179-186.

44. Jemt $T$ \& Hedegard B (1982) Reproducibility of chewing rhythm and of mandibular displacements during chewing. J Oral Rehabil 9, 531-537.

45. Allison PJ, Peyron MA, Faye M \& Hennequin M (2004) Video evaluation for mastication validation in persons with Down's syndrome. Dysphagia 19, 95-99.

46. Sato S, Ohta M, Goto S, Kawamura H \& Motegi K (1998) Electromyography during chewing movement in patients with anterior disc displacement of the temporomandibular joint. Int J Oral Maxillofac Surg 27, 274-277.

47. Steiner JE, Michman J \& Litman A (1974) Time sequence of the activity of the temporal and masseter muscles in healthy young human adults during habitual chewing of different test foods. Archs Oral Biol 19, 29-34.

48. Nagasawa T, Yanbin X, Tsuga K \& Abe Y (1996) Sex difference of electromyogram of masticatory muscles and mandibular movement during chewing of food. J Oral Rehabil 24, $605-609$.

49. Nakamura $\mathrm{T}$, Inoue $\mathrm{T}$, Ishigaki $\mathrm{S}$, Morimoto $\mathrm{T} \&$ Maruyama $\mathrm{T}$ (1989) Differences in mandibular movements and muscle activities between natural and guided chewing cycles. Int J Prosthodont 2, 249-253.

50. Mioche L, Hiiemae KM \& Palmer JB (2002) A postero-anterior videofluorographic study of the intra-oral management of food in man. Archs Oral Biol 47, 267-280.

51. Kohyama K, Mioche L \& Bourdiol P (2003) Influence of age and dental status on chewing behaviour studied by EMG recordings during consumption of various food samples. Gerodontology 20, 15-23.

52. Gavião MB, Engelen L \& Van der Bilt A (2004) Chewing behaviour and salivary secretion. Eur J Oral Sci 112, 19-24.

53. Krall E, Hayes C \& Garcia R (1998) How dentition status and masticatory function affect nutrient intake. J Am Dent Assoc 129, 1261-1269.

54. Lamy M, Mojon P, Kalykakis G, Legrand R \& Butz-Jorgensen E (1999) Oral status and nutrition in the institutionalized elderly. J Dent 27, 443-448.

55. Sahyoun NR, Lin CL \& Krall E (2003) Nutritional status of the older adult is associated with dentition status. J Am Diet Assoc 103, 61-66.

56. Hartsook EI (1974) Food selection, dietary adequacy, and related dental problems of patients with dental prostheses. J Prosthet Dent 32, 32-40. 